\title{
Justicia transicional y pueblos indígenas en Colombia: breve genealogía de una intersección
}

\author{
Ginna Marcela Rivera Rodríguez / Universidad de los Andes
}

La justicia transicional como paradigma ortodoxo y representación de los itinerarios de una sociedad que pretende moverse de un pasado/presente violento a otro estadio social futuro de no violencia/paz, se ha construido sobre la idea del universal que viaja (Tsing 2005), como heredera de normas jurídicas internacionales y meticuloso ritual de utilidad política que encuentra su base fundacional en epistemologías legales propias del pensamiento liberal y de los derechos humanos para la promoción del Estado de Derecho y de la democracia (Hoogenboom 2014, 226). En estos términos, los dispositivos y contenidos de la justicia transicional han sido dotados de una aparente cualidad de transportabilidad que ha permitido que sean implementados en geografías y lugares del dolor bien diversos, siendo hoy en día, la respuesta estatal más normalizada para enfrentar contextos de violencia y de tránsito socio/político (Arthur 2009, Teitel 2003).

Los procesos de burocratización y tecnificación de lo transicional a nivel mundial han sido asimilados en distintos órdenes nacionales durante un periodo que abarca las últimas tres décadas (Bell 2009, Elster 2004), convirtiéndose en "un campo de conocimiento especializado y en un ámbito de intervención política altamente institucionalizado" alrededor del cual "se articulan centros de investigación, agencias multilaterales y un sinnúmero de sistemas de regulación, tanto de tipo político (como el poder de sanción del Consejo de Seguridad de las Naciones Unidas), como de orden jurídico (por ejemplo, el establecimiento del Estatuto de Roma y la Corte Penal Internacional)" (Jiménez 2008, 36). En el marco de esta expansión del "paradigma no cuestionado" (Richmond y Franks 2009, 5) el proyecto transicional se forjó en estrecha conjunción con valores y principios que como afirma Hoogenboom "siguen privilegiando ciertos vocabularios sobre otros. Incluso el llamado a un enfoque más holístico es meramente una palabra de moda para adoptar una serie de mecanismos que todavía se derivan de las teorías dominantes" $(2014,232)$.

Así, en los distintos ejemplos de implementación de la apuesta transicional que, incluyen regiones del globo tan disímiles como Sudáfrica, Chile, Perú, Guatemala, Ruanda, Sierra Leona, o Argentina (Roht-Arriaza y Mariezcurrena 2006, Fletcher y Weinstein 2015) tras el reconocimiento de hechos violentos, vino la creación de instancias de justicia para investigar las violaciones a los derechos humanos, la persecución, indulto y/o amnistía a los perpetradores, la búsqueda de la verdad y la formulación de programas de reparación, en un continuo casi inercial que por encima de la complejidad de las violencias, resultó privilegiando la estabilidad y la finalidad de la propuesta, es decir, la producción y reproducción de subjetividades y sociedades capaces de hacer el mismo recorrido, la misma transición (Hoogenboom 2014, 228).

Con estas reflexiones como contexto y en respuesta a la poca atención que el modelo de la justicia transicional prestó por mucho tiempo a nociones no hegemónicas del cambio y la transformación social (Franzki y Olarte 2012, 201), durante la última década han emergido perspectivas críticas (Schnabel 2007, McEvoy y McGregor 2008, Coxshall 2005) que señalan no solo, la excesiva centralidad en los aspectos jurídicos y formales de las transiciones, sino también los problemas de las prácticas descontextualizadas de la aplicación de sus mecanismos. Estas discusiones tuvieron eco en el ámbito de las ciencias sociales y permitieron la proyección de una agenda de investigación y debate que, comprometida, con los lugares y los sujetos de la violencia (Shaw 2010, Theidon 2006, Viaene 2010, Arriaza y Roht-Arriaza 2008), promovió la apertura al estudio de otras formas de justicia, como medio para mover los marcos conceptuales de la justicia transicional "permitiendo que las críticas, las prioridades y las prácticas locales nos muestren formas alternativas de conceptualizar la justicia y los derechos" (Okello 2010, 277).

De este modo, analítica y empíricamente se hicieron explícitas las desconexiones entre el proyecto legalista liberal e internacional y las prioridades locales, lo cual contribuyó a develar — en términos de Rosalind Shaw (2010, 3-4) — cómo el paradigma de la justicia transicional se desestabiliza por sus aplicaciones en los lugares y tiempos de los sobrevivientes/ víctimas (Viaene 2013,93). Así las cosas, las prácticas transicionales fueron interpeladas por no considerar con suficiente atención el dinamismo y la multiplicidad de los significados $\mathrm{y}$ visiones del mundo donde fueron implementadas, como por desvirtuar la diversidad de las experiencias de violencia que en estos se expresaban (Castillejo 2015, 26-29).

Esta perspectiva basada en los lugares de las transiciones dio forma a una fundamentación teórica que orienta también al presente escrito, y que localiza la justicia transicional (Shaw 2010) para producir un desplazamiento del centro de las pautas y mecanismos estandarizados a la exploración 
de los encuentros periféricos y de las intersecciones con los conceptos de (en) la vida (Vasco 2007, 19), las relaciones cotidianas y las expectativas de las personas que enfrentan la violencia. Shaw describe este esfuerzo como un estudio de "las formas concretas en que estos mecanismos se cruzan con las prácticas, los puntos de vista y las prioridades de los sobrevivientes en lugares y momentos específicos $\mathrm{y}$, por lo tanto, modifican las interpretaciones convencionales de lo 'local', la 'justicia' y las 'transiciones”' $(2010,25)$.

El ejercicio de localización de la justicia transicional propone, de acuerdo con Alejandro Castillejo (2014, 216), un cambio de escala analítica con la que emergen interpretaciones locales sobre las violencias y el sufrimiento subjetivo/ colectivo, como factores comprensivos de las fracturas del orden de la vida, de las relaciones cotidianas que las primeras generan, así como de las posibles salidas y formas de enfrentarlas. (Das 2008, Jimeno 2011). De ahí que, el foco de interés sean los registros "otros" que resultan externos y marginales a la ortodoxia transicional, al tiempo que se visibilizan los espacios que quedan entre las prácticas concretas y los tipos conceptuales/ideales (Coxshall 2005, 209). Interpelar así al discurso transicional supone reconocer que los lugares y sujetos de la violencia representan visiones del mundo más dinámicas de las que el modelo contempla y que son capaces, por lo tanto, de complejizar su aparente uniformidad y consenso (Castillejo 2015), y de desarrollar, reproducir y/o reinterpretar nociones particulares de dolor, justicia, daño y reparación, entre otros.

En estos términos del debate que proponen los estudios críticos de las transiciones (Castillejo 2017) el presente ensayo encuentra su base de reflexión, con el propósito de aportar a la comprensión del encuentro entre lo transicional y lo indígena en Colombia desde una observación localizada de algunos de los lenguajes, espacios y prácticas que en éste se producen. Con el soporte del trabajo etnográfico, a partir de una revisión documental y de un análisis genealógico de la (co)producción normativa de los últimos 15 años, se presenta una lectura que da cuenta de los movimientos y desarrollos de la estatalidad colombiana en la dinámica y compleja intersección con el proyecto transicional y el campo de las experiencias de violencia y los mundos de la vida de los pueblos indígenas en el país.

\section{La transición localizada}

Colombia es un país de conflictos históricos y estructurales cuya más reciente expresión ha dado lugar a cerca de seis décadas de enfrentamientos entre actores económicos y armados de la estatalidad, la paraestatalidad y las guerrillas. En este contexto, la población civil y entre ella, líderes, autoridades y organizaciones étnicas, han sido sujetos de acciones de violencia, y sus territorios, focos de disputa por el control de recursos e intereses estratégicos para el sostenimiento de los regímenes y las atrocidades de la guerra (Villa y Houghton 2004, Espinosa 2007, Corte Constitucional de Colombia 2009).

Así, pese a que los indígenas han exigido "que sus territorios sean respetados y considerados como zonas neutrales y de paz" (Villamizar 2007, 328) la cotidianidad de la confrontación armada les ha significado el encuentro con la desaparición, el desplazamiento, el confinamiento forzado, el debilitamiento de la gobernanza propia y las múltiples expresiones de la muerte. Estas violencias han apuntado a "debilitar su vida colectiva con los principios que la sustentan y afectar sus espacios culturalmente significativos" (Salamanca 2015); por ende, han representado fracturas inmediatas, graves y directas a la continuidad y la eficacia de las estructuras sociales, económicas, políticas y culturales que son fundantes para estos pueblos.

En medio del conflicto armado en el país, el Estado colombiano emprendió desde hace más de una década el trámite por la vía institucional, de posibles salidas para su "terminación", depositando en el modelo globalizado de la justicia transicional la ilusión y las promesas de cambio (Castillejo 2017). ${ }^{1}$ De este modo, se instalaron con contundencia en el lenguaje y las políticas nacionales medidas judiciales, mecanismos políticos, instancias y oficinas de gobierno, con sus respectivos encuadres normativos y encargos administrativos y presupuestales.

Pese a este proceso de "asimilación formal" e impulso estatal del discurso transicional, desde los primeros años varios son los sujetos y lugares que han disputado los sentidos de este proyecto y que confrontan su aplicación, desde la demanda de ejercicios de contextualización y análisis de la violencia ${ }^{2}$. Dichos análisis, entre muchos otros aspectos, cuestionan la idea de una justicia transicional sin transición, identifican impactos diferenciados en las poblaciones y territorios, respuestas sociales al conflicto y a la construcción de paz que no hacen parte del ámbito de acción del Estado, o incluso, aproximaciones sociales que conceptualizan de manera distinta a las víctimas, los victimarios y la justicia (Téllez 2007, CODHES 2016, Gómez 2013).

Uno de estos ámbitos de interpelación a la justicia transicional tiene su base epistemológica en la conformación pluricultural del país, por la cual comunidades étnicas y pueblos indígenas han interrogado los presupuestos del modelo jurídico/político (CIT 2011, Talco 2008, Bacca 2009, Rivera 2014). En este sentido, tomaron forma inquietudes sobre la lectura de la justicia transicional frente a las subjetividades impactadas por el conflicto, el alcance de las medidas de reparación frente a la continuidad de las violencias históricas, la manera como responde el discurso transicional a las dimensiones del conflicto armado y de la desigualdad que han vivido los pueblos indígenas, las especificidades que se expresan, en las 
interpretaciones de estos pueblos, sobre lo que puede o no ser una víctima, sobre el concepto de dolor, o sobre lo que entienden por verdad, justicia y reparación, entre otros importantes aspectos. Este espacio de interpelación de las organizaciones y pueblos indígenas del país a las apuestas transicionales estatales ha generado un campo de intersección en el que las epistemologías, conceptos de la vida e interpretaciones sobre la violencia y los modos para enfrentarla se han expresado, como sigue.

\section{El campo de la intersección}

La reparación debe ser reparada. Yo necesito entender la palabra porque eso es lo que se dice afue$\mathrm{ra}$, pero no sé hasta dónde recoja lo espiritual de nuestro sentido. Porque si no nos encontramos con eso ¿cómo dialogamos? Hay que curar desde el origen, donde se fecundó y nació el desorden, desde el pensar, así tenemos que intencionarlo.

Si reparar significa sanar, hay que hermanarnos para sanar la Sierra, para sanarla desde el corazón. ${ }^{3}$

Lorenzo Izquierdo, Indígena Arhuaco

Hace un poco más de diez años en el territorio de la Sierra Nevada de Santa Marta pregunté a Lorenzo Izquierdo del pueblo indígena Arhuaco por el significado de eso que el Estado llamaba reparación, pregunta que fue respondida por él con sorpresa y un poco de burla señalando "nosotros no somos carros dañados. ¿Cómo es eso que debemos ser reparados? Yo creo que la reparación es la que debe ser reparada" (Notas de campo. Conversación en Gun Aruwun, Sabana Crespo, 2008). Producto de este diálogo con Lorenzo lo que pareció hacerse presente, en primera medida, es que el concepto de reparación - como uno de los elementos centrales de la propuesta de la justicia transicional - no conectaba de manera evidente y directa con la lengua y el pensamiento indígena Arhuaco. Para Lorenzo las palabras reparar/reparación hacían parte de un conjunto de referentes conceptuales que no encontraban símil con su comprensión, a los que, además, veía asociados con una "mecanización" de lo humano, como expresó en su interpretación literal "nosotros no somos carros dañados". De este modo, el acercamiento al lenguaje transicional desde este contexto localizado se dio en medio del reflejo de un extrañamiento y del reconocimiento de su carácter extranjero, a lo que le siguió la urgencia de dotarlo de sentido(s) a partir de la lectura y visión particular del mundo que, para Lorenzo encontraban mejor expresión en las palabras sanar y armonizar. El contexto histórico de esta conversación tenía como principal referente jurídico/ político el proceso de implementación de la ley 975 de 2005, mejor conocida en Colombia como ley de justicia y paz. Esta ley fue uno de los primeros acercamientos de la institucionalidad con el discurso transicional cuya configuración y puesta en marcha enfrentó al Estado con dificultades como el escaso impacto generado para la solución del conflicto armado en su complejidad y con sus múltiples actores, por la generación de una idea de paz fragmentaria y parcial (Uprimny et.al. 2006, 43), la falta de garantías para el desmantelamiento de las estructuras paramilitares (Comisión Colombiana de Juristas 2005, 1-2), la debilidad en la generación de espacios para la participación de las víctimas (Garzón 2011, 229-231), la ineficacia en la protección de los derechos, la ausencia de coordinación interinstitucional y hasta la falta de recursos humanos, logísticos y económicos para poner en marcha el proyecto (Forer 2017,4).

A lo anterior se sumó el hecho de que con la apuesta normativa de justicia y paz el Estado colombiano siguió una lógica de actuación de "arriba hacia abajo" (Gómez 2013), que fruto del acuerdo entre élites políticas y económicas con los grupos paramilitares, privilegió una lectura estandarizada de lo transicional sin reconocer las demandas y particularidades de los lugares de la violencia en Colombia. Para el caso específico de interés de este ensayo, esto suprimió cualquier tipo de referencia y/o reconocimiento a la perspectiva étnica, la multiculturalidad y los sujetos indígenas del país. Así las cosas, la relación que se instauró desde los primeros documentos transicionales con los pueblos indígenas, fue una de invisibilización de la pluralidad, de poca comprensión y acercamiento a sus nociones propias; en últimas, de equiparación de su experiencia con la de las "otras víctimas" (Castillejo 2015, 26).

El efecto rebote que tuvo esta perspectiva vino con la implementación posterior de los mecanismos transicionales en los territorios; es decir, cuando los indígenas empezaron a hablar de y desde su propio dolor. Esta(s) violencia(s) específica(s) estaba(n) llena(s) de múltiples caras, profundidades y traslapes, se trataba de un continuo pluralizado de dolores superpuestos, históricos y sistemáticos (Jaramillo 2011, Villa y Houghton 2004) que superaban los estrechos marcos temporales de la normatividad transicional y que se expresaban en el tiempo presente con los lenguajes del pasado, las relaciones de poder y los daños transhistóricos (Castillejo $2015,27)$ de la colonia, la república, las misiones de evangelización, el narcotráfico, las guerrillas, los paramilitares, las empresas y el "desarrollo" (Jimeno 2015, Escobar 2010). Emergieron así limitaciones de los conceptos de lo transicional en clara tensión con las múltiples temporalidades de la violencia sobre lo indígena, los sujetos múltiples del daño y la historicidad de la reparación (Rodríguez y Lam 2011).

Este primer escenario de institucionalización de las violencias vividas por los indígenas tuvo desarrollos posteriores que, por una parte, evidenciaron un cambio significativo en la postura y en la comprensión del Estado, y por 
otra, fueron resultado de la incidencia y la participación de la representatividad indígena en los espacios de formulación de los preceptos y políticas transicionales. Uno de los hitos más importantes en este sentido, tuvo como eje articulador la promulgación de la ley 1448 de 2011, o ley de víctimas, y su correspondiente reglamentación en el decreto 4633 del 9 de diciembre de 2011 por medio del cual se dictaron medidas de asistencia, atención, reparación integral y de restitución de derechos territoriales a las víctimas pertenecientes a los pueblos y comunidades indígenas y se estableció de acuerdo al artículo 128 que "el Estado garantizará las condiciones para que las medidas de reparación integral, así como de protección de derechos y prevención garanticen efectivamente el derecho fundamental a la consulta previa" (Decreto 4633 de 2011).

Esta disposición, como los demás preceptos del decreto en relación con las medidas de reparación, puso de presente la necesidad de que se materializara un diálogo respetuoso con la pluralidad y la diversidad de interpretaciones sobre la violencia y la vida en el mundo indígena. En este contexto, el Estado puso en marcha un proceso de consulta en el que participó la instancia de representación oficial de los pueblos indígenas como es la Mesa Permanente de Concertación (Ruiz $2017,91)$ que autorizó para el derecho colombiano nuevas nociones de daño, reparación y víctima.

Como resultado de esta consulta, el lenguaje de la norma transicional favoreció el reconocimiento de la diversificación de los sujetos del dolor, de manera que ya no solo las personas indígenas en su individualidad, sino los pueblos como unidades integradoras y colectivas aparecieron "adoloridos" y/o susceptibles de ser dañados por la violencia, junto con sus territorios, como cuerpos vivos, cuya capacidad sintiente/sufriente también fue adicionada al decreto por incidencia de los indígenas. Esto último se refleja en el artículo 3 del decreto que señala que "para los pueblos indígenas el territorio es víctima, teniendo en cuenta su cosmovisión y el vínculo especial y colectivo que los une con la madre tierra", y se profundiza en el artículo 45 en el que refiriéndose a los daños al territorio se señala:

El territorio, comprendido como integridad viviente y sustento de la identidad y armonía, de acuerdo con la cosmovisión propia de los pueblos indígenas y en virtud del lazo especial y colectivo que sostienen con el mismo, sufre un daño cuando es violado o profanado por el conflicto armado interno y sus factores vinculados y subyacentes y vinculados. Son daños al territorio aquellos que vulneren el equilibrio, la armonía, la salud y la soberanía alimentaria de los pueblos indígenas y que puedan entenderse conexos con las causas a las que se refiere el artículo $3^{\circ}$ del presente decreto. (Decreto 4633 de 2011)
Esta última incorporación fue una de las más innovadoras de la reglamentación porque, como se ha dicho, las violencias a los pueblos indígenas en Colombia han buscado un debilitamiento de las bases de su vida colectiva, afectar sus espacios culturalmente significativos y mermar sus posibilidades para el control territorial y el ejercicio de la autonomía, por ende, tiene sentido que, si la violencia se ejerce sobre los espacios y tiempos de los indígenas, que la reapropiación de estos pueda ser producida como medida de reparación. Además, esto dialoga directamente con las demandas de ampliación, titulación y recuperación territorial que hacen parte del conjunto de reivindicaciones históricas de los pueblos étnicos que, han logrado ser expresadas de manera inteligible para el lenguaje estatal del reconocimiento positivo de derechos, permeando marcos normativos y jurisprudenciales en el país. De este modo, tal y como señala Daniel Ruiz “(...) la Ley de Víctimas fue un escenario en el que estas organizaciones pudieron articular demandas en términos que fueron al mismo tiempo consecuentes con las realidades experimentadas a causa del conflicto y sintonizadas con el lenguaje propio de los derechos que han sido ya reconocidos por el Estado" $(2017,108)$.

La especificidad de esta reglamentación muestra cómo la experiencia de los pueblos indígenas basada en sus conceptualizaciones, permitió una trasmutación de las nociones estandarizadas de lo transicional, evidenciando nuevas y más complejas relaciones y maneras de abordar los impactos y realidades de la violencia en Colombia, lo cual se constituye en una oportunidad "para hacer visible una variedad de daños ocasionados a un conjunto disímil de seres donde lo humano es apenas una instancia más, y no siempre la más importante" (Ruiz 2017, 90).

Se evidencia con esto, un ejercicio de coproducción de la transicionalidad en el que los pueblos indígenas exigen al Estado un nivel de interrelación más cercano y respetuoso con sus categorías explicativas del mundo que pueden verse recreadas y dinamizadas, así como los dispositivos y lenguajes transicionales resultar enriquecidos. Fruto de este movimiento de los márgenes interpretativos sobre la violencia se posibilita también una ampliación de los alcances y sentidos de las medidas de reparación que, si pretenden ser legítimas y dialogantes con la diversidad cultural y la complejidad social de los conflictos en el país, "tendrían que orientarse al restablecimiento de relaciones entre la gente, sus territorios y los demás seres presentes" (Ruiz 2017, 99).

No obstante, es de aclarar que desde nuestra perspectiva el restablecimiento y armonización de las relaciones no se originan ni en los marcos jurídicos ni en las políticas de intervención del Estado. En ello, están directamente implicados los actores sociales, y para el caso que nos compete, los pueblos indígenas con sus diferentes instancias autónomas de gobierno e identidad cultural, las prácticas rituales que usan "para trabajar sobre la violencia del pasado y del presente como un medio para vivir con malos entornos" así como las "prácticas 
de reparación que no involucran rituales, sino que se basan en el performance de la vida diaria para restablecer las relaciones" (Shaw 2010, 20)

Ahora bien, algunos desarrollos normativos y políticos posteriores, los cuales hoy en día permiten hablar de múltiples transicionalidades o de proyectos transicionales paralelos y superpuestos en el país, se produjeron alrededor del proceso de negociación en La Habana (2012-2016), entre el gobierno nacional y la guerrilla de las Fuerzas Armadas Revolucionarias de Colombia (FARC). ${ }^{6}$ Luego de que "las comunidades étnicas y culturales tuvieron que esperar cuatro años antes de ser invitadas, y solo pudieron participar en las discusiones acerca del sexto y último punto de las negociaciones, sobre las modalidades de ratificación de los Acuerdos" (Braconnier 2018, 117) como consecuencia de un nuevo proceso de incidencia y perseverancia de las organizaciones se consideró "fundamental incorporar la perspectiva étnica y cultural, para la interpretación e implementación" del Acuerdo Final para la terminación del conflicto y la construcción de una paz estable y duradera (2016). En este acuerdo el capítulo étnico fijó como principios básicos de la relación con los grupos étnicos:

a la libre determinación, la autonomía y el gobierno propio, a la participación, la consulta y el consentimiento previo, libre e informado; a la identidad e integridad social, económica y cultural, a los derechos sobre sus tierras, territorios y recursos, que implican el reconocimiento de sus prácticas territoriales ancestrales, el derecho a la restitución y fortalecimiento de su territorialidad, los mecanismos vigentes para la protección y seguridad jurídica de las tierras y territorios ocupados o poseídos ancestralmente y/o tradicionalmente. (Acuerdo 2016, 208-209)

La perspectiva étnica y cultural desde la que los pueblos interrogaron al acuerdo entre las FARC y el gobierno, buscó introducir aspectos diferenciales y territoriales a cada uno de los elementos centrales que lo constituyen (reforma rural integral, participación política, fin del conflicto, solución al problema de las drogas ilícitas víctimas del conflicto); asimismo se buscó posicionar el respeto a sus instancias y autoridades propias de justicia, exigiendo, entre otras, la apertura de espacios y mecanismos de coordinación con el Estado y participación en la implementación de lo que se conoce a partir del Acuerdo como el Sistema Integral de Verdad, Justicia, Reparación y No Repetición del que hacen parte la Comisión para el Esclarecimiento de la Verdad, la Convivencia y la No Repetición; la Unidad para la Búsqueda de Personas dadas por Desaparecidas en el contexto y en razón del conflicto armado y la Jurisdicción Especial para la Paz.

La implementación del capítulo étnico en cuestión y de los acuerdos en general está en desarrollo actualmente, presentando atrasos y obstáculos de orden político, económico e institucional que están siendo analizados por diferentes actores (Misión de Verificación de las Naciones Unidas en Colombia 2018, Instituto Kroc de Estudios Internacionales de Paz 2018, Fundación Ideas para la Paz 2018, Contraloría General de la República 2018), incluidas las organizaciones y representantes de los pueblos étnicos (Comisión Étnica para la Paz y la Defensa de los Derechos Territoriales 2018).

Pese a que las densidades y el fondo de este complejo proceso, superan por mucho los esfuerzos de este ensayo, lo que es posible referenciar es que los ámbitos discursivos indígenas sobre la violencia siguen intersectándose cada vez más estrechamente con aspectos de lo transicional, en un nivel de especialización que ya no solo moviliza conceptos, interpretaciones y categorías de la vida indígena a los lenguajes normativos y jurídicos del Estado, sino que proporciona criterios de acción y de formulación de medidas diferenciales, diversifica instancias de seguimiento y control a las políticas estatales e incluso llega a integrar en "cuerpo propio" las instancias e instituciones transicionales con personas provenientes de los pueblos y territorios indígenas, como sucede con la Jurisdicción Especial para la Paz y la Comisión para el Esclarecimiento de la Verdad. ${ }^{7}$

Todos estos desplazamientos de la estatalidad colombiana en las interacciones con los pueblos indígenas permiten plantear algunas consideraciones analíticas adicionales frente a la manera en que los mecanismos transicionales pueden encontrar en la perspectiva de lugar, otras formas de fundamentar sus acciones que, basadas en las condiciones, prácticas, sentidos, subjetividades y prioridades locales lleven a una concepción más diversa de la justicia; develen mayores dinamismos en los conceptos; evidencien las contradicciones y abstracciones de la propuesta transicional; conecten las posibilidades del discurso con las realidades concretas de los afectados; examinen críticamente las implicaciones prácticas, las deficiencias y las aplicaciones de los principios de la justicia de transición y cuestionen algunas de sus "verdades" que empiezan a aparecer como inmodificables. Al respecto, las siguientes reflexiones y argumentos finales.

\section{A guisa de cierre}

Al esfuerzo analítico sobre los aspectos estudiados corresponde agregar una mención sobre el hecho mismo de los movimientos y giros de la transicionalidad, y es que estos son solo posibles en la medida que los pueblos indígenas y, sus diferentes instancias de organización y representación, disputan y defienden decididamente para sí, la apertura de procesos de participación y diálogo democrático e intercultural. Se trata de una apuesta que, resulta por demás, valiente y ejemplificante, al considerarse el histórico patrón de relaciones de discriminación y racismo que ha prevalecido en la 
actuación del Estado colombiano desde los primeros tiempos republicanos frente a los pueblos indígenas.

Este trámite por las "vías institucionales" de las reivindicaciones históricas de los grupos étnicos confirma su voluntad política y sus cada vez más activas labores de incidencia en ámbitos tecnificados como el derecho para enfrentar las problemáticas que llegan a sus territorios, y entre ellas, a la violencia a la que han estado y siguen estando expuestos. De acuerdo con Julieta Lemaitre "es en contraste con esta violencia, como un mentís a la misma, que el derecho y sus promesas son atractivos no sólo como herramienta para obtener beneficios concretos sino como visión del mundo (la nación multicultural) que alivia la angustia generada por la persistencia de la colonización a sangre y fuego" $(2009,344-345)$.

En medio de ello, la violencia y los impactos que genera en los pueblos y territorios indígenas, logran un nivel de visibilización que resulta importante y necesario, y las posibilidades para el diálogo plural y la construcción de políticas estatales se dotan de elementos que tienen mayores y mejores posibilidades de llegar a ser efectivas para impactar las realidades de estas comunidades. De este modo, el ejercicio de localización de la justicia complejiza sus operaciones, momentos y categorías y puede contribuir a hacer de su implementación una más legítima, al generar aproximaciones y comprensiones respetuosas de las personas y los territorios que viven la violencia.

Por otro lado, podría decirse que como resultado de esta interacción entre los indígenas y la transicionalidad, las instancias de representación de los pueblos étnicos pueden verse fortalecidas con la incidencia, disputa y traducción de los términos de las "nuevas" relaciones que quieren tener con el Estado. Sin embargo, no son los pueblos los que resultan fundamentalmente favorecidos con este proceso, sino la institucionalidad y el paradigma de la justicia transicional que en su carácter estado-centrista, tal y como plantea Alejandro Castillejo $(2018)^{8}$ termina reinscribiendo al Estado sobre sí mismo, y la transición, por ende, permitiendo que éste se transforme sobre la base de sus propios fundamentos, arquitecturas legales e institucionales.

Esta reinscripción se expresa no solo en la literalidad del derecho y de la formulación de los marcos normativos específicos como los analizados en este escrito, sino en la reedificación de oficinas, políticas públicas, agencias de gobierno y plataformas que solidifican y expanden los mecanismos que permiten que opere y se haga legible el poder del Estado sobre los indígenas/ciudadanos. El Estado que se produce como resultado de ello, es solo uno aparentemente fortalecido, pues las inercias institucionales, la presión de los intereses de actores políticos, armados y económicos relacionados con la violencia y la persistencia de las bases que dieron origen al conflicto, reactualizan sus debilidades y ponen en entredicho el aparente poderío de la institucionalidad.
La contundencia del fenómeno de la ineficacia del derecho es un ejemplo de esto, el cual, para el caso de los pueblos indígenas, fue nominado como brecha de implementación por el ex Relator Especial de Naciones Unidas para los Derechos Humanos y las Libertades Fundamentales de los Indígenas, Rodolfo Stavenhagen (2006). Este concepto hace referencia a las enormes distancias que existen entre los reconocimientos positivos y normativos de derechos para los pueblos indígenas y sus realidades cotidianas "en las que se encuentran numerosos problemas para el adecuado cumplimiento de estas medidas" (Martínez, Juan y Hernández 2018, 14).

Dado que el campo jurídico de la transicionalidad no escapa a los problemas estructurales del acceso a la justicia en Colombia y de la inaplicabilidad del derecho, estos reconocimientos normativos con toda la novedad y pluralidad que se les puede reconocer siguen reproduciendo la mencionada brecha de implementación en materia de derechos de los pueblos indígenas, no solo porque sus condiciones materiales no han tenido un impacto significativo, sino porque las estructuras complejas de la violencia siguen intactas y han sobrevivido al proceso de transición del país. Por cuestiones centrales como estas, la relación desde el lenguaje y las herramientas del derecho entre los pueblos indígenas y el Estado se da de manera ambivalente, en un contexto "donde las afirmaciones de confianza en el derecho conviven con la descripción constante de su ineficacia" (Lemaitre 2009, 346).

Considerando entonces que como argumenta Rachel Sieder "la marginación, la pobreza, la discriminación y la violencia que aquejan a los pueblos indígenas no se resolverán con el derecho" resulta necesario que no se sobredimensionen "los instrumentos y procesos legales, ni mucho menos transformarlos en fetiches" $(2011,317)$. De ahí que, en paralelo a los formalismos de la disputa jurídica, los pueblos indígenas sigan siendo sujetos de otros campos de fuerza y de acciones de orden más político y cultural en los que los discursos de la resistencia, la negación de la vulnerabilidad y la exigibilidad ante el Estado prevalecen. Tal y como expresa la líder Arhuaca Leonor Zalabata:

Si bien es cierto que la violencia ha cobrado numerosas vidas y ha debilitado las estructuras propias de la organización y, por ende, de su cultura, los indígenas han luchado por mantener sus principios y valores alejados de la violencia, cumpliendo así con la Ley de Origen. Esto solamente es posible si se actúa como una sociedad unida, con sólidos referentes de identidad y con unos objetivos comunes y claros. Para lograrlo es necesario ejercer una activa resistencia pacífica de manera decidida y coordinada, (...); cualquier decisión que se tome o cualquier acción que se lleve a cabo implica la relación directa con la cultura y el territorio, de ahí la importancia de permanecer y defenderlos. (Misión de Apoyo al Proceso de 
Paz de la Organización de los Estados Americanos en Colombia 2008, 17)

En medio de esta complejidad, la resistencia cultural, la permanencia en los territorios, la vitalidad e incidencia activa en los espacios abiertos para la creación de estatalidad hacen parte del proceso de coproducción y de localización de la transicionalidad en Colombia, de la que los pueblos indígenas han sido partícipes. Las intersecciones y los intercambios dinámicos que de ello han resultado "pueden promover la creatividad o inhibirla, suscitar la resistencia o disiparla" (Wolf 1982, 5), y si no, en todo caso, permiten plantear una problematización y pluralización más que urgente de las transiciones.

\section{Obras Citadas}

Arriaza, Laura y Naomi Roht-Arriaza. 2008. "Social Reconstruction as a Local Process." The International Journal of Transitional Justice 2 (2): 152-72.

Arthur, Paige. 2009. "How 'Transitions' Reshaped Human Rights: A Conceptual History of Transitional Justice.” Human Rights Quarterly 31 (2): 321-67.

Bacca, Paulo. 2009. “Tiempo Y Espacio De Las Reparaciones Colectivas Para Los Pueblos Indígenas Víctimas De La Violencia”. En Rodrigo Uprimny Yepes. et. al. Reparaciones en Colombia: análisis y propuestas, p.p. 169-217. Bogotá, Universidad Nacional de Colombia.

Bell, Christine. 2009. “Transitional Justice, Interdisciplinarity and the State of the 'Field' or 'Non-Field.” 3 (1): 5-27.

Braconnier, Laetitia. 2018. "The Own Rights of Ethnical People in the Colombian Peace Agreement of August 2016 | Los Derechos Propios de Los Pueblos Étnicos En El Acuerdo de Paz de Agosto de 2016." Revista Derecho Del Estado, no. 40: 113-26.

Castillejo, Alejandro. 2014. "La Localización Del Daño: Etnografía, Espacio, y Confesión En El Escenario Transicional Colombiano.” Horizontes Antropológicos 42: 213-36.

Castillejo, Alejandro. 2015. "La Imaginación Social Del Futuro: Reflexiones Sobre Colombia y El Prospecto de Una Comisión de Verdad." En Proceso de Paz y Perspectivas Democráticas En Colombia, edited by CLACSO, 13-43. Ciudad Autónoma de Buenos Aires.

Castillejo, Alejandro. 2017. La Ilusión De La Justicia Transicional: Perspectivas Críticas Desde El Sur Global. Editado por Alejandro Castillejo Cuéllar. Primera Edición ed. Colección General. Bogotá: Universidad De Los Andes, Facultad De Ciencias Sociales, Departamento De Antropología, Ediciones Uniandes.

Confederación Indígena Tairona -CIT. (2011). Propuestas para el programa de garantías de los derechos fundamentales de los pueblos indígenas de Colombia. Valledupar.

CODHES. 2016. Guía Para La Reparación Colectiva de Los Pueblos y Comunidades Afrodescendientes En El Marco Del Decreto Ley 4635 de 2011. Editado por CODHES. Bogotá.

Comisión Colombiana de Juristas-CCJ. 2005. Sin paz y sin justicia. Boletín No 6. Bogotá.

Comisión Étnica para la Paz y la Defensa de los Derechos Territoriales. 2018. 1 Informe De Cumplimiento Del Capítulo Étnico En El Marco De La Implementación Del Acuerdo Final De Paz Entre El Gobierno De Colombia Y Las FARC-EP. Bogotá.

Contraloría General de la República. 2018. Segundo Informe Al Congreso Sobre La Ejecución De Los Recursos Y Cumplimiento De Las Metas Del Componente Para La Paz Del Plan Plurianual De Inversiones 1 De Enero 2017 A 30 De Marzo De 2018.

Corte Constitucional de Colombia. 2009. Auto 004. Magistrado ponente Manuel José Cepeda 
Coxshall, Wendy. 2005. "From the Peruvian Reconciliation Commission to Ethnography: Narrative, Relatedness, and Silence." PoLAR: Political and Legal Anthropology Review 28 (2): 203-22.

Das, Veena. 2008. “La Antropología Del Dolor”. En F. Ortega (Ed.), Veena Das: Sujetos del dolor, agentes de dignidad (pp. 409-436). Bogotá.

Elster, Jon. 2004. Closing the Books: Transitional Justice in Historical Perspective. Cambridge: Cambridge University Press.

Escobar, Arturo. 2010. Territorios de Diferencia. Lugar, Movimientos, Vida, Redes. Envión Edi. Vol. 1. Popayán, Colombia: Impreso por Samava Impresiones.

Espinosa, Mónica L. 2007. "Memoria Cultural y El Continuo Del Genocidio: Lo Indígena En Colombia.” Antípoda, Revista de Antropología y Arqueología, no. 5: 53-73.

Fletcher, L. E. y H. M. Weinstein. 2015. "Writing Transitional Justice: An Empirical Evaluation of Transitional Justice Scholarship in Academic Journals.” Journal of Human Rights Practice 7 (2): 177-98.

Forer, Andreas. 2017. "Proceso de Justicia y Paz en Colombia. Análisis retrospectivo y algunos logros alcanzados". En E. Cortés (Ed.), Proceso de Justicia y Paz. Evaluación y aportes en casos de Pueblos Indígenas. Editorial Universitaria de la Costa EDUCOSTA: 1-75. Bogotá.

Franzki, Hannah y Maria Carolina Olarte. 2012. "Understanding the Political Economy of Transitional Justice A Critical Theory Perspective." En Transitional Justice Theories, editado por Susanne Buckley-Zistel, Teresa Koloma Beck, Christian Braun, and Friederike Mieth, GlassHouse, 201-21. New York.

Fundación Ideas para la Paz. 2018. Las Garantías De Seguridad: Una Mirada Desde Lo Local. Desafíos Para La Protección De Las Comunidades, Los Líderes Sociales Y Los Excombatientes.

Garzón, Baltazar. 2011. Diagnóstico de Justicia y Paz en el Marco de la Justicia Transicional en Colombia. Organización de los Estados Americanos y Misión de Apoyo al Proceso de Paz. Bogotá.

Gómez, Gabriel. 2013. “Justicia Transicional ‘Desde Abajo’: Un Marco Teórico Constructivista Crítico Para El Análisis de La Experiencia Colombiana.” Co-Herencia 10 (19): 137-66.

Hoogenboom, David Anton. 2014. “Theorizing ‘Transitional Justice.”” University of Western.

Instituto Kroc de Estudios Internacionales de Paz. 2018. Segundo Informe Sobre El Estado Efectivo De Implementación Del Acuerdo De Paz En Colombia. Diciembre 2016 - mayo 2018.

Jaramillo, Pablo. 2011. “Reparaciones Indígenas y El Giro Del ‘Giro Multicultural.”" Revista Colombiana de Antropología 47 (2): 151-71.

Jiménez, Sandro. 2008. "Etnografía y Crisis: Algunos Debates y Una Práctica de Investigación En Contextos de Violencia." Nómadas 29: 34-49.

Jimeno, Myriam, Varela, Daniel y Castillo, Ángela. 2011. "Experiencias de Violencia: Etnografía y Recomposición Social En Colombia." Sociedade e Cultura 14 (2): 275-85.

Jimeno, Miriam, Varela, Daniel y Castillo, Ángela. 2015. Después de La Masacre: Emociones y Política En El Cauca Indio. Bogotá.

Lemaitre, Julieta. 2009. El Derecho Como Conjuro: Fetichismo Legal, Violencia y Movimientos Sociales. Bogotá: Siglo Del Hombre, Uniandes. 
Martínez, Juan Carlos, Víctor Juan y Violeta Hernández. 2018. Derechos Indígenas, Entre La Norma y La Praxis Reflexiones a Partir Del Seminario Internacional: Cerrando La Brecha de Implementación. Editado por Fundación Konrad Adenauer. Bogotá.

McEvoy, Kieran, and Lorna Mcgregor. 2008. Transitional Justice from below : Grassroots Activism and the Struggle for Change. Human Rights Law in Perspective. Oxford: Hart.

Misión de Apoyo al Proceso de Paz de la Organización de los Estados Americanos en. 2008. La Memoria Como Forma Cultural de Resistencia. LOS ARHUACOS. Bogotá.

Misión de Verificación de las Naciones Unidas en Colombia. 2018. Informe del Secretario General. Consejo de Seguridad de Naciones Unidas.

Okello, Moses. 2010. “Elevating Transitional Local Justice or Crystallizing Global Governance?” Localizing Transitional Justice : Interventions and Priorities after Mass Violence, 275-84.

Richmond, Oliver P. y Jason Franks. 2009. Liberal Peace Transitions : Between Statebuilding and Peacebuilding. Edinburgh: Edinburgh University Press.

Rivera, Ginna. 2014. “Avances Jurisprudenciales y Legislativos Del Derecho a La Reparación a Pueblos Indígenas Como Víctimas de Violaciones de Derechos Humanos.” Tesis de Maestría en Derecho. Universidad Nacional de Colombia. Bogotá.

Rodríguez, Cesar, y Yukyan Lam. 2011. “Etnorreparaciones: La Justicia Colectiva Étnica y La Reparación a Pueblos Indígenas y Comunidades Afrodescendientes En Colombia.” Documentos Dejusticia. Bogotá.

Roht-Arriaza, Naomi y Javier Mariezcurrena, eds. 2006. Transitional Justice in the Twenty-First Century: Beyond Truth versus Justice. Cambridge: Cambridge University Press.

Ruiz, Daniel. 2017. "El Territorio Como Víctima. Ontología Política y Las Leyes de Víctimas Para Comunidades Indígenas y Negras En Colombia.” Revista Colombiana de Antropología 53 (2): 85-113.

Salamanca, Carlos. 2015. “Bahía Portete, La Masacre Y El Ritual. Violencia Masiva, Mediaciones Y Prácticas Transversales De Memoria En La Guajira.” Antípoda 21: 121-143.

Schnabel, Albrecht, Chesterman, Simon y Pouligny, Béatrice. 2007. After Mass Crime : Rebuilding States and Communities. Tokyo: United Nations University Press.

Shaw, Rosalind. 2010. "Linking Justice with Reintegration? Ex-Combatant and the Sierra Leone Experiment.” En Localizing Transitional Justice: Interventions and Priorities after Mass Violence, editado por Rosalind Shaw, Lars Waldorf y Pierre Hazan, Stanford U, 111-32. Stanford.

Sieder, Rachel. 2011. "Pueblos Indígenas y Derecho(s) En América Latina." En El Derecho En América Latina. Un Mapa Para El Pensamiento Jurídico Del Siglo XXI, editado por César Rodríguez, Siglo XXI, 303-23. Buenos Aires.

Stavenhagen, Rodolfo. 2006. "Los Derechos De Los Pueblos Indigenas.” Anuario De Derecho Constitucional Latinoamericano, 18.

Talco, Jasaima. 2008. "Para Los Kankuamos La Reparación Colectiva Pasa Por La Consolidación de Nuestro Territorio Tradicional." Etnias \& política. Revista Del Observatorio Indígena de Políticas Públicas de Desarrollo y Derechos Étnicos 8: 170-75.

Teitel, Ruti. 2003. “Genealogía de La Justicia Transicional.” Harvard Human Rights Journal 16 (1997): 69-94.

Téllez, Ana María, Sanchez, Nathalie, Tejada, Carolina y Villa, Juan David. 2007. Nombrar Lo Innombrable: Reconciliación Desde La Perspectiva de Las Víctimas. CINEP. Bogotá. 
Theidon, Kimberly. 2006. "Justice in Transition: The Micropolitics of Reconciliation in Postwar Peru." Journal of Conflict Resolution 50 (3): 433-57.

Tsing, Anna. 2005. Friction: An Ethnography of Global Connection. Anthropology. Globalizaton Studies. Environmental Studies. Princeton, NJ: Princeton University Press.

Uprimny, Rodrigo, Saffon, María Paula, Botero, Catalina y Restrepo, Esteban. 2006. ¿Justicia Transicional Sin Transición? Verdad, Justicia y Reparación Para Colombia. Editado por Ediciones Antropos. Verdad, Justicia y Reparación Para Colombia. Dejusticia. Bogotá. papers3://publication/uuid/4BC807A2-9DBC-4406-82EE-1E0DBB7DE6A7.

Vasco, Luis Guillermo. 2007. “Así Es Mi Método En Etnografía.” Tabula Rasa, no. 6: 19-52.

Viaene, Lieselotte. 2010. “Life Is Priceless: Mayan Q'eqchi' Voices on the Guatemalan National Reparations Program.” The International Journal of Transitional Justice 4 (1): 4-25.

Viaene, Lieselotte. 2013. "La Relevancia Local de Procesos de Justicia Transicional. Voces de Sobrevivientes Indígenas Sobre Justicia y Reconciliación En Guatemala Posconflicto.” Antipoda, no. 16: 85-112.

Villa, William y Houghton, Juan. 2004. "Evolución General de La Violencia Politica Contra Los Pueblos Indigenas.” En Violencia Política Contra Los Pueblos Indígenas En Colombia 1974-2004, 19-49. Bogotá: IWGIA CECOIN OIA.

Villamizar, Darío. 2007. "Paramilitarismo y Pueblos Indígenas: Otra Mirada Al Conflicto." En Parapolítica. La Ruta de La Expansión Paramilitar y Los Acuerdos Políticos, editado por Cerec and Corporación Nuevo Arco Iris, 323-62. Bogotá.

Wolf, Eric. 1982. Europa y La Gente Sin Historia. 2nd ed. Ciudad de México: Fondo de Cultura Económica.

\section{Notas}

1. Ver al respecto: Línea del tiempo: mecanismos de justicia transicional en Colombia del Centro Internacional para la Justicia Transicional. Disponible en: https://www.ictj.org/sites/default/files/subsites/colombia-linea-tiempo/index.html?gclid=-CjwKEAjw uvHBRDUkumF0tLFp3cSJACAIHMYX6nKqL2eHp3T5Pst5BQ1OdeAraKK6Tao37k9D88Y5hoCtijw wcB. $\% 20$ Fecha $\% 20$ de $\% 20$ consulta $\% 2023 \% 20$ de $\% 20$ enero $\% 20$ de $\% 202019$

2. La integración del proyecto transicional a las políticas del Estado colombiano tuvo procesos y matices problemáticos por cuestiones de espacio y de enfoque analítico no se pueden desarrollar integralmente en el presente texto.

3. Se refiere a la Sierra Nevada de Santa Marta (SNSM), territorio de los indígenas Iku (Arhuacos), Wiwa, Kággaba (Kogui) y Kankuamo. La SNSM es un macizo montañoso ubicado al norte de Colombia declarado por la UNESCO como Reserva de Biosfera y Patrimonio de la Humanidad en 1979, por su riqueza cultural y ambiental. Como una de las montañas más altas del mundo a orillas del mar, su geografía se levanta hasta los $5.775 \mathrm{msnm}$ y abarca los departamentos del Magdalena, Cesar y Guajira (CIT 2011).

4. Mónica Espinosa $(2007,57)$ hace referencia al "continuo del genocidio" como categoría que "permite aproximar la institucionalización de formas de violencia que se han convertido en patrones estructurales de poder y que, hasta hoy, están inmersos en prácticas habituales y cotidianas de marcación, jerarquía, estigmatización, control y agresión - esta última a veces indirecta y subterránea- contra ciertos grupos humanos."

5. Un análisis localizado de la justicia transicional daría cuenta de cómo "las comunidades movilizan rituales y elementos simbólicos transicionales para enfrentar las profundas divisiones dejadas o acentuadas por los conflictos civiles" (Theidon 2006, 436) y de cómo estas prácticas plurales escapan al monopolio estatal pero se relacionan de maneras muy específicas con las políticas institucionales de la transicionalidad que, pueden actuar ante ellas tanto como facilitadoras como entorpecedoras. 
6. Esta referencia en plural a la justicia transicional permite denotar, que en el caso colombiano existen de manera simultánea, proyectos y normativas transicionales cuya superposición e interacción hacen parte del contexto de trabajo desde el que se plantea esta reflexión. Esta referencia se la debo a Alejandro Castillejo (Comunicación personal 17 de abril de 2017, Bogotá).

7. La conformación de la Jurisdicción Especial para la Paz consideró a los magistrados indígenas Ana Manuela Ochoa (pueblo Kankuamo), Juan José Cantillo (pueblo Wayuu), José Miller Hormiga (pueblo Totoró) y Belkis Florentina Izquierdo (Pueblo Arhuaco). Por su parte, Patricia Tobón Yagarí (pueblo Embera) integra la Comisión de Esclarecimiento de la Verdad

8. Me refiero aquí a las discusiones del Seminario "Convivencia y reconstrucción del tejido social" dirigido por Alejandro Castillejo. Sesión del 12 de septiembre de 2018 "Devenir Estado y Reinscripción sobre sí Mismo." Facultad de Ciencias Sociales de la Universidad de los Andes. Bogotá, Colombia. 